\title{
6 Cinefilia na Bahia: a atuação de Walter da Silveira e a formação cinéfila
}

Rafael Oliveira Carvalho*

\section{Resumo}

O crítico e pesquisador Antoine de Baecque (2010) possui uma definição bastante pertinente ao que ele tem como ideal de cinefilia: "vida que organizamos em torno dos filmes", como toda uma cultura construída ao redor da experiência do cinema e seus desdobramentos. É a partir dessa noção, cabendo uma série de inflexões e de outras posições sobre a cinefilia, que tentaremos aqui apreender de que forma a vida cultural baiana na época em que Walter da Silveira se fez atuante - especialmente entre as décadas de 1950 e 1960 -, propagando sob várias vertentes - crítica, cineclubista, pedagógica - seu discurso apaixonado sobre o cinema, pôde ser formatada na então provinciana Bahia que ia ganhando seu status de centro econômico e cultural.

Palavras-chave: Walter da Silveira, cinefilia, Bahia.

\begin{abstract}
The film critic and researcher Antoine de Baecque (2010) has a very pertinent definition to what he thinks the ideal of cinephilia is: "life that we organize around the movies", as a whole culture built around the experience of cinema and its aftermaths. It is from this notion, with a mount of inflections and other exposures about the cinephilia, we will try to apprehend how the cultural life of Bahia at Walter Silveira's lifetime - especially between the 1950s and $1960-$, propagating under various strands - critical, as a film society, teaching - his impassioned speech about the film, could then be formatted in the provincial Bahia that was gaining status of economic and cultural center.
\end{abstract}

Keywords: Walter da Silveira, Cinefilia, Bahia. 


\section{Introdução}

Partindo do encantamento do cinema enquanto a mais nova atração cultural e grande invenção do século XX, ganhando depois o gosto pela análise e reflexão das imagens em movimento e culminando com o próprio fazer cinematográfico que aflorou na região, a Bahia passou, em meio a esse percurso, por diversas mudanças sociais, culturais e políticas que podem ser sentidas através do valor que o cinema ganhou no estado. Dessa forma, o trabalho desenvolvido por Walter da Silveira abarca um período de mudanças e renovações que pesam sobre o pensamento baiano formado sobre a sétima arte, tendo contribuído em muito para seu desenvolvimento. Nas palavras de José Umberto Dias (2006, p. 19 20):

Dossiê Cinema e Audiovisual: entre o sensível e o reflexivo Arquivos do CMD, Volume 3, N. 1. Jan/Jul 2015 Aeração de Walter da Silveira emerge historicamente dessa encruzilhada cinética que permitirá integrar-se à potência das idéias cinematográficas no que elas dispõem de aproximação imediata aos mais longínquos e espalhados rincões. Internacionaliza e internaliza

a reprodução em massa da imagem em movimento que vem suscitar uma nova dinâmica da noção de temporalidade, ampliando, estreitando e montando cordéis de reunião gestual da humanidade.

Vivia-se, na década de 1950, uma das maiores transformações sociais, políticas, econômicas e culturais de que a Bahia foi palco: os anos do governo Juscelino Kubitscheck (19561961) e sua proposta desenvolvimentista. Com o famoso slogan "Cinquenta anos em cinco", o presidente pôs em prática o Plano de Metas, uma política de caráter nacionalista, com projetos de modernização, urbanização e industrialização por todo o país (CARVALHO, 1999). Com a modernidade batendo à porta, nota-se um crescimento do próprio movimento cultural baiano e de seus artistas, com reconhecimento no restante do país.

No âmbito do cinema, o nome de Walter da Silveira ganha destaque, nas terras baianas, como um grande defensor e ativista em prol da propagação da arte cinematográfica. Se o cinema chega à
Bahia como um espetáculo de entretenimento para o grande público, o esforço de Silveira como militante cultural está em tratá-lo de forma artística, digna de atenção e apreço, fazendo ver, através da experiência cinéfila, essas potencialidades que se sobressaem à 
${ }^{1}$ Importante lembrar que Silveira era formado em Direito e exerceu durante toda a sua vida a profissão de advogado. Sua proximidade e paixão pelo cinema, portanto, atravessam sua carreira como uma militância apaixonada e não como meio de vida. diversão pura e simples. Nossa proposta aqui é entender como as noções de cinefilia podem ser aplicadas ao trabalho que Silveira desenvolveu, não só como crítico e ensaísta de cinema, mas como cineclubista, professor e pesquisador da sétima arte.

\section{Walter da Silveira: um ativista cultural}

Walter da Silveira, crítico ou ensaísta de cinema, cineclubista e professor. Essas são algumas das atividades que o reconhecido intelectual baiano exerceu em torno das discussões da arte cinematográfica na Bahia. Ele se tornou figura respeitada e referenciada como quem detinha um conhecimento acumulado sobre o cinema, uma espécie de mentor intelectual de toda uma geração de pessoas que mantinham contato com as movimentações em torno do cinema. Nas palavras de André Setaro (2010, p. 52), “a partir de Walter, os baianos começaram a considerar o cinema autêntico veículo da expressão artística". Centrado nessa trajetória em muitas frentes, é importante desenharmos os passos e lições de cinefilia que Silveira legou à sociedade baiana através de suas atividades ${ }^{1}$.
A criação do Clube de Cinema da Bahia (CCB), levada adiante pelo próprio Silveira em parceria com o amigo Carlos Coqueijo Costa, em junho de 1950, certamente é um dos marcos dessa nova forma de lidar com a experiência do cinema. O Clube trará para a região filmes de diretores importantes da época que faziam sucesso no mundo e já eram reconhecidos como grandes nomes da sétima arte, da mesma forma que resgatava obras clássicas mais antigas com o intuito de se fazê-las conhecer pelo público baiano. Porém, não possuía a intenção de se tornar uma bandeira contra o cinema hollywoodiano, muito embora seguisse outro caminho de preocupação estética. Nas palavras do seu próprio fundador:

O Clube de Cinema não fora criado para combater o cinema americano. Seus objetivos se limitavam a valorizar o filme como expressão de arte. A impressão reinante de início era, todavia, a de que se tratava de uma entidade antiamericanista. Dois motivos conduziam a essa impressão: os filmes europeus, fora do mercado exibidor, custavam baratíssimo e necessitavam de uma tela qualquer; e as agências de Hollywood, numa política erradíssima contra o movimento cine-clubista, recusavam sua produção (SILVEIRA, 1978, p. 84). 
De qualquer forma, o CCB foi um marco para o pensamento cinematográfico baiano, pois possibilitou a muitos jovens e intelectuais o alargamento da experiência do cinema, promovendo uma nova visão dos produtos que faziam parte de uma tradição narrativa e formal diferentes do classicismo dos filmes norteamericanos, muito embora os bons exemplares dessa filmografia também tivessem espaço garantido nas exibições e discussões do Clube. Alia-se a isso a própria verve educativa de Silveira que promovia verdadeiras palestras depois das exibições dos filmes Segundo aponta Maria do Socorro Carvalho (1999, p. 181-182):

O CCB produziu, ao longo dos anos, uma platéia interessada em cinema. Não apenas no cinema enquanto 'diversão', mas, sobretudo, como 'expressão de arte' e, portanto, com uma linguagem própria que deveria ser analisada, estudada, debatida para poder ser plenamente fruída.

Dessa maneira, o $\mathrm{CCB}$ se firma como alternativa cinematográfica para os amantes da sétima arte e reduto de cinéfilos e intelectuais que descobriam os prazeres do cinema "alternativo". De acordo com José Umberto Dias (1978, p. II), no posfácio do livro póstumo de Walter da Silveira, o Clube foi fundado e montado seguindo os preceitos do "modelo francês", sendo inicialmente instalado no auditório da Secretaria de Educação e Saúde, contando com o apoio do então secretário Anísio Teixeira. O CCB era constituído por um quadro de quase 300 sócios, entre escritores, artistas plásticos, advogados, professores de medicina e universitários da época. Além disso, segundo Dias (1978), as finalidades do Clube não se resumiam somente à exibição de filmes de valor artístico, mas também na organização de uma biblioteca especializada, bem como de uma filmoteca, na realização de cursos, debates e conferências e também na publicação de um periódico.

As exposições que Silveira fazia sobre os filmes ao final de cada sessão do CCB podem ser vistas como uma própria extensão da crítica cinematográfica, exercida numa série de jornais e revistas publicadas no estado. A atividade crítica/jornalística constitui, na verdade, a gênese do trabalho de Silveira, desenvolvida ainda muito precocemente, tendo começado a escrever nos jornais baianos já em 1928, com apenas 13 anos de idade.

Esse período inicial de produção textual de Silveira, que vai do final dos anos 1920 até início dos 40, é o momento de 
encantamento pela indústria do cinema (especialmente a produzida nos Estados Unidos e, em menor escala, na França) que buscava espalhar sua influência, hegemonia e modelo narrativo a várias partes do globo. É aí que Silveira começa a escrever para alguns periódicos, seduzido por aquele cinema de celebridades. Esse início é marcado pelo comentário rápido, notas de divulgação de determinado filme estrelado por algum ator ou atriz conhecido, ainda sem a preocupação crítica e estética da qual o jornalismo só irá se munir e se interessar tempos depois. Os textos de Silveira desse período, não assinados, não passavam de pequenas notas de caráter predominantemente informativo sobre filmes de maior sucesso que estavam em exibição na capital baiana.

$\mathrm{O}$ amadurecimento cinematográfico do jovem Walter vai se dando aos poucos, em decorrência do próprio crescimento pessoal e das reflexões que vai realizando no percurso de aprofundamento da história e das obras cinematográficas. Para Dias (2006), esse crescimento vai se tornar visível na primeira metade da década de 1940, mais especificamente quando, em 1943, profere a conferência Cinema - arte contemporânea, a convite da União dos Estudantes da Bahia (UNB). Posteriormente, o texto da exposição será publicado no Diário de Notícias. É desse período também que começa a florescer no pensamento reflexivo de Silveira a defesa por uma produção cinematográfica nacional, atestada pelo artigo $E$ hora do cinema nacional, além de engrossar as defesas do cinema enquanto forma artística com o texto Valor do cinema como arte, ambos publicados pelo mesmo Dário de Notícias.

No decorrer dessa década, vão surgir nos periódicos as primeiras críticas assinadas por Silveira, destinadas a discutir mais especificamente um filme em si a partir de suas características formais e contextuais. Segundo Carvalho (2003, p. 66), "nos artigos e livros de Walter da Silveira, predomina um enfoque estéticohistórico sobre o cinema". A partir de então, sua produção jornalística voltada para o cinema se reveza entre os ensaios sobre temas relacionados ao cinema, em especial sobre os cineastas que achava importante destacar e suas características autorais, e, por outro lado, as críticas de cinema que, cada vez mais, tornavam-se embasadas e aprofundadas. Será assim durante toda a trajetória de produção a partir de então. Sobre as críticas, Carvalho (2003, p. 67) pontua: 
Para ele, a função da crítica de cinema sobretudo naquele momento histórico, era conscientizar o público da necessidade de ver o cinema como expressão artística, fazendo-o compreender a importância da interpretação dos filmes para o seu aprimoramento, não somente cultural, mas, de modo amplo, nas diversas esferas do desenvolvimento humano.

E a partir desse seu lugar de formador de opinião, Silveira vai formar também pessoas para que pensem reflexivamente o cinema, sejam elas cineastas que mais tarde irão participar de movimentos de realização cinematográfica (tanto os baianos do Ciclo de Cinema da Bahia ou alguns embrionários do Cinema Novo), como outros indivíduos engajados que surgem como críticos de cinema. É o caso de nomes como os de Glauber Rocha, Orlando Senna, Hamilton Correia, Geraldo Portela, Walter Lima Júnior, José Umberto Dias, Paulo Baladão e outros.

Dossiê Cinema e Audiovisual: entre o sensível e o reflexivo Arquivos do CMD, Volume 3, N. 1. Jan/Jul 2015
Ao longo dos dez primeiros anos de existência do Clube, formar-se-ia uma nova geração de expressão cinematográfica nos seus aspectos estéticos, históricos, sociais, políticos econômicos para, inclusive, facilitar a críticos de cinema, preocupados em analisar a comunicação entre os realizadores e o grande público (CARVALHO, 2003, p. 66)

Desde a década anterior, Walter da Silveira, já preocupado com a popularidade do próprio cinema e das suas discussões enquanto forma de arte, iniciava também as discussões acerca do valor e propósito da crítica cinematográfica enquanto atividade intelectual que precisava ser "organizada e consciente, responsável e sem submissões, que oriente e fiscalize seus métodos e os seus fins" (SILVEIRA, 1945, p.?). De certa maneira, trata-se de uma antecipação do valor e importância que a crítica de cinema vai conquistar nos anos 1950, momento em que o surgimento de novos intelectuais no fazer crítico irão acentuar a importância primordial desse profissional em meio aos círculos de pessoas ligadas às atividades culturais no Brasil.

Além de sua largamente referida atividade crítica e cineclubista, outra iniciativa fundamental desenvolvida por Silveira foi a criação do Curso Livre de Cinema, em 1968, ministrado na Universidade Federal da Bahia (UFBA). O curso tinha duração de um ano e, apesar de não exigir dos alunos diploma universitário para 
${ }^{2}$ As Jornadas Baianas começaram como um modesto festival de cinema na Bahia, tendo sua primeira edição em 1972 mantendo-se no calendário cultural do estado até 2011. Uma culural do estado ate 2011. Uma de suas maiores conquistas foi de manter um evento cultural com forte teor crítico em pleno governo militar no país. Depois do Festiva de Brasília, é o evento de exibição cinematográfica mais antigo do Brasil.

${ }^{3}$ Guido Araújo (1995) refere-se ao Curso como Grupo Experimental de Cinema, como o projeto passou a ser chamado depois que ele sozinho passou a dirigi-lo. Tinha largo apoio da Universidade, uma vez que Araújo era o então coordenador do Departamento Cultural da UFBA (instância que corresponde atualmente

Coordenação de Extensão) frequentá-lo, era necessário passar por um teste de seleção. Inicialmente, Silveira atuou como professor de História e Estética do Cinema, enquanto o cineasta e programador das Jornadas Baianas $^{2}$, Guido Araújo, ministrava as aulas de Teoria e Prática do Cinema. Segundo palavras do próprio Araújo (1995), a aceitação do curso demonstrou a relevância que um empreendimento de caráter educativo como aquele teve na Bahia:

Esse $\mathrm{Grupo}^{3}$ despertou grande interesse. A primeira turma foi enorme, demonstrando o desejo da juventude baiana e dos artistas, de um modo geral, de realizar algo nesse sentido. Foi extremamente agradável aquele convívio, num ano atípico e transitório. Já estávamos sob a ditadura, mas naquela fase de movimentos, que foi 1968 .

Do Curso Livre de Cinema, serão formados importantes realizadores e críticos de cinema na Bahia, como os cineastas André Luiz Oliveira, diretor do clássico do Cinema Marginal Meteorango Kid - O Herói Intergalático, José Umberto Dias, Ney Negrão, além do crítico e professor André Setaro.
Ademais as atividades docentes, o Curso serviu também para desenvolver na Universidade práticas de cineclubismo, voltada para toda a classe estudantil da instituição, cujos sábados eram marcados pela exibição de diversos filmes no Salão Nobre da Reitoria. Além disso, tendo à frente dois professores tão engajados em prol da cinematografia nacional e baiana, foi importante para legitimar a produção brasileira, em especial os rumos do movimento cinemanovista que estava em alta naquele final da década de 1960, ainda mais pelo lugar de "liderança" que o baiano Glauber Rocha ocupava no movimento e na cinematografia brasileira.

Mas já em 1969 Silveira abandou as atividades do Curso Livre de Cinema por conta das complicações de saúde que diagnosticaria mais tarde como um câncer. Mesmo assim, o Curso permaneceu em pleno funcionamento, coordenado por Guido Araújo até a primeira metade da década de 1970.

Nesse percurso de pesquisador e professor preocupado com a ampliação do conhecimento que envolvia o cinema, destaca-se também o engajamento de Silveira em refletir sobre a receptividade do cinema na Bahia desde o seu princípio e também a importância cultural e histórica que passou a ter na região. Isso fica demarcado

Dossiê Cinema e Audiovisual: entre o sensível e o reflexivo

Arquivos do CMD, Volume 3, N. 1. Jan/Jul 2015 
${ }^{4}$ Desde muito cedo em sua carreira, Silveira sempre teve larga adoração pelo trabalho do cineasta nortepelo trabalho do cineasta norteamericano Charles Chaplin, tendo escrito uma série de ensaios sobre os filmes e o projeto estético do diretor-roteirista-ator-produtor. Esse livro, portanto, é a consumação de todo o esforço intelectual desenvolvido há muito tempo sobre a carreira de Chaplin. no lançamento póstumo de A História do Cinema Vista da Província (1978), livro que vinha sendo preparado por Silveira muito tempo antes de sua morte, deixado inconcluso quando ele veio a falecer no ano de 1970. Para Carvalho (1999, p. 184-185),

\begin{abstract}
Seus estudos sobre o cinema brasileiro eram realizados nessa mesma perspectiva, acrescidos de uma postura corajosa e enriquecedora: situava a experiência cinematográfica brasileira, e particularmente a baiana, no interior da história do cinema mundial, como atesta seu livro póstumo.
\end{abstract}

Ainda no final de sua vida, Silveira irá publicar o livro de ensaios Fronteiras do Cinema (1966), na verdade uma reunião de ensaios e artigos publicados em diversos periódicos; e, posteriormente, seria a vez de lançar Imagem e Roteiro de Charles Chaplin $^{4}$ (1970), poucos meses antes de sua morte.

Segundo Dias (2006), todas essas atividades podem ser pensadas como um importante complemento ao projeto de expansão da cultura cinematográfica que Silveira desempenhava através das várias atividades das quais tomava a frente, tendo o cinema como objeto de estudo e admiração, seja como crítico, ensaísta, cineclubista, pesquisador, professor; enfim, como pensador do cinema. Basta analisarmos agora de que forma essa rica trajetória constituiu uma base para a configuração de uma cinefilia na Bahia.

\section{Cinefilia na Bahia}

Sou de uma geração desencantada, a que descobriu o cinema às vésperas do fechamento das salas: salas de bairro já há algum tempo transformadas em oficinas mecânicas ou lojas, salas de cineclubes desertadas em prol da telinha, salas de arte e experimentação parisienses em plena reestruturação. Entretanto soube rapidamente que "isso" existia, a cinefilia, essa vida que organizamos em torno dos filmes (BAECQUE, 2010, p. 31).

Apesar de tratar a cinefilia como algo já acabado no tempo em que se apaixonava pelo cinema em fins da década de 1970, pertencente a um lugar e tempo pretéritos bem definidos na história do cinema, nomeadamente a França das décadas de 1950 e 60, o crítico e pesquisador Antoine de Baecque marca aí uma definição bastante pertinente ao que tem como ideal de cinefilia: "vida que 
${ }^{5}$ Os autores apontam como traços dessa efusão cinéfila as discussõe provocadas pelas revistas de crítica especializadas Cahiers du Cinéma e Positif, a construção teórica da politica dos autores e florescimento da Nouvelle Vague (ambos tendo origem no interior d redação dos Cahiers) e os debates de cinéfilos em cinemas como Cinema MacMahon e outros. organizamos em torno dos filmes", como toda uma cultura construída ao redor do cinema e seus desdobramentos. É a partir dessa noção, cabendo uma série de inflexões e de outras posições sobre a cinefilia, que tentaremos aqui apreender de que forma a vida cultural baiana na época em que Walter da Silveira se fez presente pôde ser formatada na então provinciana Bahia que ia ganhando seu status de centro econômico e cultural.

Se Antoine de Baecque demarca tão rigidamente o lugar de concretização da cinefilia, essa construção é mais de ordem partidarista do que necessariamente uma definição acabada e largamente aceita. É também uma forma dele próprio se encontrar enquanto um apaixonado pelo cinema depois de passada toda a euforia, enriquecimento e desenvolvimento formador de uma geração na França. Assim, o autor prossegue:
Mas era o fim dos anos 1970 e ela [a cinefilia] não existiu por muito tempo. A palavra "cinefilia", então incessantemente proclamada, designava na realidade um amor e uma prática irremediavelmente mortos. Minha geração não poderia reinventar esse amor: os "autores" estavam consagrados, os artigos, escritos, as entrevistas, gravadas, os filmes, vistos, e às vezes revistos na televisão. Tudo já tinha acontecido (BAECQUE, 2010, p. 31).

Relativizando essa visão, Marijke de Valck e Malte Hagener (2005) conseguem enxergar a cinefilia através de uma face dupla: uma mais generalizada, como prática possível a qualquer lugar, e essa em que a tradição francesa impõe seu peso, uma vez que é impossível desconsiderar a influência que os movimentos de crítica e público tiveram e legaram ao mundo a partir da década de 1950, florescendo plenamente no decênio seguinte na França ${ }^{5}$. Os autores lembram também a origem francesa que a própria palavra cinéphile carrega. De qualquer forma, é preciso considerar o caráter generalista que esse amor ao cinema pode representar. Nessa perspectiva, a cinefilia

[...] alude ao fenômeno universal em que a experiência fílmica evoca sensações particulares de prazer intenso, resultando em uma conexão fortemente sentida com o cinema, geralmente descrita como uma relação de amor. Cinéfilos em todo o mundo continuam a ser capturados e arrebatados pela magia das imagens em movimento. Eles nutrem momentos pessoais de 
${ }^{6}$ Do original: "It alludes to the universal phenomenon that the film experience evokes particular sensations of intense pleasure resulting in a strongly felt connection with the cinema, ofte described as a relation of love. Cinephiles worldwide continue to be captured and enraptured by the magic of moving images. The cherish personal moments of discovery and joy, develop affectionate rituals, and celebrate their love in specialized communities" resuring in a strongly felt

descoberta e alegria, desenvolvem rituais afetivos e celebram seu amor em comunidades especializadas $^{6}$ (VALCK; HAGENER, 2005, p 11) [tradução nossa].

No entanto, o próprio Antoine de Baecque, paradoxalmente, irá ampliar a noção tempo-espacial da cinefilia quando ele a coloca como essa rotina que se organiza em torno do cinema. Ora, sendo assim, pensada como prática sociocultural historicamente contextualizada e codificada, ela não estaria restrita a um só momento histórico. Em outra ocasião, o autor (2010, p. 33) considera a cinefilia como "maneira de assistir aos filmes, falar deles e em seguida difundir esse discurso", o que permite que o ideário da cinefilia possa aparecer em outros contextos históricos.

$\mathrm{Na}$ Bahia, essa representação da cinefilia tem na figura de Walter da Silveira seu expoente maior, difundindo essa paixão que deixará marcas na sociedade cinéfila que se formará durante (e após) sua trajetória dedicada ao cinema. Assim, essas práticas culturais (ou cultuais, como Baecque coloca), que configuram o primeiro objeto de estudo da cinefilia (ver, comentar e difundir os filmes), marcadas então pela religiosidade com que essas atitudes são apreendidas e realizadas pela comunidade cinéfila, encontram na Dossiê Cinema e Audiovisual: entre o sensível e o reflexivo Arquivos do CMD, Volume 3, N. 1. Jan/Jul 2015 postura e influência de Silveira um modelo a ser seguido na forma como se relaciona com a experiência fílmica. Esta reafirma sua sacralidade como momento-chave de contato com a obra artística. André Setaro (2010, p. 107) relata o seguinte acontecimento que teve lugar numa das sessões do Clube de Cinema da Bahia:

Plateia e balcão do Guarany lotados. Sábado de manhã de 1965. A maioria dos espectadores constituída de estudantes da Central, que, filando aulas, adquiria o conhecimento do filme como arte. Uma turma, porém, de capadócios, que estava ali, naquela sessão, apenas para perturbar, gritava, ria e assobiava diante dos passos poéticos de Hiroshima, mon amour. Num determinado momento, Walter da Silveira, temperamental como era, levantou-se e solicitou que a projeção fosse interrompida e que as luzes da sala se acendessem. Diante da platéia, que ficou silenciosa, Walter deu um tremendo esporro nos jovens assanhados, fazendo-os ver que Hiroshima era uma obra de arte e merecia todo o respeito e todo o silêncio. Walter da Silveira não admitia que alguém saísse no meio de um filme. Ficava aborrecido e o pecador restava, depois, sem moral com o mestre. Qualquer conversinha lateral também era reprovada pelos olhos de Walter da Silveira. 
É esse tipo de atitude que aponta para uma postura de valorização da experiência fílmica, com respeito e consideração pela própria arte que tinha na sala de cinema seu lugar sagrado de recepção, aliado à própria necessidade de conhecer (e compreender) os filmes. O ver, nos termos em que Silveira impunha a uma plateia a ser formada, ganhava então uma conotação mais grave, como uma exigência a quem se predispunha a desfrutar daquele momento de contato com a obra na tela. É claro que estamos falando aqui de um púbico que frequentava o cineclube à procura de outra relação com a arte cinematográfica e não daqueles que continuavam indo aos cinemas à procura de simples passatempo. E essa relação que ia se construindo tinha no próprio interesse do público a aceitação dessas “imposições" de respeito pela exibição de um filme, fora alguns, como visto, que apareciam como figuras deslocadas naquele grupo. Mas, também, esses traços de atitude perante a arte não precisam estar restritos somente àquele lugar específico, mas se difundir como postura que os cinéfilos assumem, agora como um aprendizado que se leva para a vida. Ao mesmo tempo, ao assumi posturas como essa acima citada, Walter da Silveira acabava se tornando um guardião da própria experiência de se assistir a um filme com a devida consideração, propagando o respeito de devoção cinéfilo pelo filme a ser visto, modelando o caráter da cinefilia na Bahia.

Num segundo momento, como coloca Baecque (2010), surge a leitura da crítica como aspecto tão fundamental na cinefilia como a própria visão dos filmes. "O cinema exige que se fale dele" (BAECQUE, 2010, p. 32). Em certo sentido, não só filmes e cineastas eram adorados ou odiados pelo público cinéfilo, como também críticos e seus escritos suscitavam admirações ou aversões por parte do público, incitadas pelas posições que tomavam diante das questões relacionadas ao cinema e sobre as quais tinham voz e legitimação para escrever sobre. A crítica funciona, portanto, como prolongamento da experiência de discussão e compreensão dos filmes que, das conversas nas saídas das sessões ou nas reuniões de amigos, ganhavam as páginas dos veículos de comunicação, ampliando o debate sobre o cinema. "O ato de refletir é a marca específica da cinefilia: todas as suas práticas visam dar profundidade à visão dos filmes" (BAECQUE, 2010, p. 34). Tanto para os críticos quanto para o público cinéfilo que a consumia, a crítica era o espaço de legitimação do cinema enquanto arte valorizada, ampliando seu 
discurso para além do simples caráter informativo ou servindo como guia de consumo das obras fílmicas. Era ali o espaço para a propagação de uma paixão sob forma de um discurso ponderado (ou mesmo acalorado) sobre os filmes, seus autores, temáticas e estéticas.

Guardadas as proporções com o movimento crítico que acontecia no contexto cultural francês, a Bahia não ficava de fora desse gosto e apreço pela crítica de cinema. "Lendo Walter da Silveira descobri o cinema internacional segundo sua economia, sua política, sua técnica, sua estética, sua ideologia" (ROCHA apud CARVALHO, 1999, p. 183). Se Walter da Silveira era obviamente a referência mais importante para a crítica cinematográfica desenvolvida na Bahia, até pela trajetória como redator "especializado" nos assuntos de cinema nos periódicos baianos desde muito novo, sua influência e relevância está também no incentivo para o surgimento de um discurso crítico que ganha espaço na mídia através de outros nomes ligados à cena cultura baiana. Segundo reconhece Paulo Emílio Salles Gomes (1962, p 242),

Dossiê Cinema e Audiovisual: entre o sensível e o reflexivo Arquivos do CMD, Volume 3, N. 1. Jan/Jul 2015
Os esforços de Walter da Silveira, entretanto, não foram perdidos. Os jornais da Bahia são hoje os que dispõem dos críticos cinematográficos mais jovens e entusiastas do país. Numa revista literária como Ângulos, as seções mais estimulantes e polêmicas são as que se dedicam ao esforço da compreensão e da análise da conjuntura cinematográfica brasileira.

Se essa riqueza crítica tem sua centralidade no próprio trabalho longevo de Silveira, ela pode ser notada no surgimento de um discurso profícuo nos periódicos baianos, resultado não só da necessidade que se criou naqueles sujeitos pensantes de falar sobre cinema, mas também da legitimação de um público que, acredita-se culturalmente mais interessado, recebia com bons olhos e apreço a discussão que ia se fazendo sobre o cinema, formando assim um olhar mais apurado sobre o que antes era visto somente como espetáculo.

Depois, então, como aponta Baecque (2010), é preciso difundir os filmes, as boas obras, as experiências que o cinema pode fornecer, os rituais e rotinas com os quais esses filmes devem ser vistos, difundir as discussões em torno das obras, as próprias críticas, debates e disputas intelectuais sobre os mais variados 
O exemplo mais famoso e notável dessa prática encontra-se no livro Hitchcock/Truffaut, en que o crítico e cineasta francês entrevista 0 realizador de origem inglesa, discorrendo sobre cada um dos filmes de Hitchcock. assuntos ligados ao cinema, enfim, esse amor pela arte que se resolveu abraçar. Encarar a sétima arte a partir de uma militância apaixonada é essencial, justamente o que Silveira conseguia fazer na Bahia, como projeto de vida, através de todas as atividades engajadas em torno do cinema das quais tomava frente, como vimos aqui anteriormente. Com todas as suas iniciativas e trabalho, o intelectual do cinema se revela, no fundo, um grande cinéfilo formando outros cinéfilos.

Outro ponto crucial nessa empreitada de difusão cinéfila está em se fazer reconhecer os bons diretores, trazer à luz aqueles que ainda são desconhecidos ou mesmo criar a fama de outros que até então não são bem vistos pelo público e pelo campo artístico. É nesse sentido que a cinefilia cumpre um papel legitimador de alguns realizadores, elevando a carreira de alguns deles, em especial com o advento da política dos autores pelos redatores dos Cahiers $d u$ Cinéma. Os discursos críticos ganham aí fôlego para defender certos realizadores que serão tratados agora como autores de seus filmes por conseguirem injetar neles uma "personalidade" marcante, traços estéticos e temáticas específicas, aspectos próprios que os diferenciariam de outros realizadores. Foi assim que nomes como os de Alfred Hitchcock, Howard Hawks, Samuel Fuller, Nicholas Ray (existia um apreço muito grande por cineastas de dentro da indústria hollywoodiana que não eram reconhecidos nos Estados Unidos) e Roberto Rossellini, por exemplo, ganharam status de grandes mestres do cinema, defendidos e amados nas páginas das revistas e nos debates. Daí que eram feitas retrospectivas e mostras dedicadas a recuperar a filmografia desses cineastas, vista como um conjunto coeso, com seus traços comuns de autoralidade, e os próprios cineastas eram convidados a dar entrevistas, participar de debates, falar sobre seus próprios filmes ${ }^{7}$.

É aí que, na Bahia, Silveira, mais uma vez, revela a importância de pensar a crítica como aquela que aponta os bons nomes de quem faz cinema naquela atualidade. Charles Chaplin é o mais evidente nesse sentido pela admiração que Silveira já nutria por ele desde muito cedo e pelo livro que lhe dedicou mais tarde, mas também foi um defensor e propagador da obra de Federico Fellini, Ingmar Bergman, Michelangelo Antonioni, Roberto Rossellini, Akira Kurosawa, Alain Resnais. A diferença aqui é que alguns desses cineastas chegam a Silveira (e à Bahia) com o status de autor já demarcado, até mesmo pelo atraso com que os filmes são 
vistos. O que lhe cabe é reforçar essa admiração, fazendo ver o talento artístico desses autores, sem descobrir ele mesmo os diretores que poderiam, da mesma forma, ser elevados a essa distinção.

Principalmente por essa última questão, a de consagrar certos cineastas em quem pouco se prestava atenção, é que Antoine de Baecque (2010) aponta a cinefilia como produtora de uma contracultura, indo em direção contrária aos valores culturais vigentes. A política dos autores tem esse espírito, com a finalidade também de chamar a atenção para a discussão da arte cinematográfica e para a necessidade de enxergar o cinema sob novas perspectivas, agora através de um olhar jovem, renovador. A cinefilia, de diário íntimo, de paixão particular, ganha amparo em uma coletividade pensante e passa a ser a história de uma prática, de uma forma de olhar. Traça seu percurso como um "caminho para o conhecimento", uma maneira de "conhecer pela forma" (BAECQUE, 2010, p. 39). Conforme o autor, a cinefilia transfere para o cinema as práticas e critérios da cultura clássica:
A cinefilia produz assim uma contracultura muito particular. Para defini-la, podemos afirmar que ela extrai, do cursus honorum universitário, seus critérios de aprendizagem (a erudição, a acumulação de um saber) e de julgamento (a escrita e a inclinação pelo classicismo), e, do militantismo político, seu engajamento (o fervor e o devotamento), para transferi-lo para outro universo de referências (o amor ao cinema) (BAECQUE, 2010, p. 41-42).

"Se o cinema é a metáfora das relações comunitárias no século XX ocidental, a cinefilia seria sua versão clandestina, seu prolongamento individual sob a forma de um ritual íntimo" (BAECQUE, 2010, p. 34). Desse ritual, os escritos de Walter da Silveira vão ser sua carta de intenções, seu manifesto em forma de conhecimento difundido, de paixão propagada, de registro histórico. Apesar de todas as atividades que desempenhou, é nos seus textos que deixou registrada uma forma de olhar, pensar, sentir e adorar o cinema que se via na província da Bahia. 


\section{Considerações finais}

Preocupado e também confiante pela formatação de um momento propício para o cinema, Walter da Silveira sempre se engajou na liderança de ações e atividades que elevassem a experiência cinematográfica numa Bahia em que se encontrava espaço para isso. Essa faceta múltipla faz dele um intelectual consciente da sua condição de agitador em prol da cultura, mas também um sempre entusiasta das possibilidades de educação e formação cultural através do cinema.

Apesar de ser muito forte em seus textos e suas falas a necessidade de "educar" as pessoas para ver o que ele estava considerando como o "bom" cinema, tal qual um guia que indicava os melhores caminhos, obras e autores, seus discursos analíticos acabavam ensinando o público leitor a ver o cinema com olhos mais apurados, a dar atenção a certo tipo de filme que estava longe da mera proposta de entretenimento que tomava o mercado exibidor, mas sem desconsiderar esse filão de mercado, de forma a incentivar o pensamento cinéfilo diante da sétima arte.
Um tanto diferente do berço da cinefilia francesa em que frutificou o ideal de valorização e paixão sobre a experiência do cinema, assim como nenhum lugar possui as mesmas configurações socioculturais, a Bahia teve sua própria conformação históricocontextual em que foi possível o surgimento de um pensamento cinematográfico específico e, consequentemente, de uma cinefilia própria, mas não muito diferente dos caminhos e possibilidades que ela propicia em torno do ver, falar e difundir o cinema. Silveira, como expoente dessa movimentação cultural, desenvolveu todo um trabalho de difusão, mas especialmente de adoração à sétima arte que ficou marcado na história da arte cinematográfica baiana.

\section{Referências}

ARAÚJO, Guido. "A história da Jornada de Cinema da Bahia". Revista O Olho da História. Salvador, BA, vol. 1, n. 1, 1995. Disponível em: http://www.oolhodahistoria.ufba.br/o1guido.html.

BAECQUE, Antoine de. Cinefilia: invenção de um olhar, história de uma cultura. São Paulo: Cosac Naify, 2010.

CARVALHO, Maria do Socorro Silva. A Nova Onda Baiana: cinema na Bahia 1958/1962. Salvador: EDUFBA, 2003. 
Imagens de Um Tempo em Movimento: cinema e cultura na Bahia nos anos JK (1956-1961). Salvador: EDUFBA, 1999.

DIAS, José Umberto. "Repensar o cinema". In: SILVEIRA, Walter da. A história do cinema vista da província. Salvador: Fundação Cultural do Estado da Bahia, 1978

Proêmio In: SILVEIRA, Walter da Walter da Silveira. $O$ eterno e o efêmero (Organização: José Umberto Dias). Salvador: Oiti Editora e Produções Culturais LTDA, 2006. 4 v.

GOMES, Paulo Emilio Salles. "Na Bahia a coisa é séria". In SILVEIRA, Walter da. Walter da Silveira. O eterno e o efêmero. (Organização: José Umberto Dias). Salvador: Oiti Editora e Produções Culturais LTDA, 2006, v. 4, p. 241-243.

SETARO, André. Escritos sobre Cinema: trilogia de um tempo crítico. (Organização: Carlos Ribeiro). Salvador: EDUFBA: 2010. 3

SILVEIRA, Walter da. A história do cinema vista da província. Salvador: Fundação Cultural do Estado da Bahia, 1978.

"A função da crítica cinematográfica". In: Walter da Silveira. O eterno e o efêmero. (Organização: José Umberto Dias). Salvador: Oiti Editora e Produções Culturais LTDA, 2006. V. 1, p. 137-138.

\section{Dossiê Cinema e Audiovisual: entre o sensível e o reflexivo}

Arquivos do CMD, Volume 3, N. 1. Jan/Jul 2015
Walter da Silveira. O eterno e o efêmero. (Organização: José Umberto Dias). Salvador: Oiti Editora e Produções Culturais LTDA, 2006. $4 \mathrm{v}$

VALCK, Marijke de; HAGENER, Malte. "Down with Cinephilia? Long live Cinephilia? And other videosyncratic pleasures". In: (Org). Cinephilia: movies, love, memories. Amsterdam: Amsterdam University Press, 2005, p. 11-23. 